\title{
Study of hot deformation of an Al-Cu-Mg alloy using processing maps and microstructural characterization
}

\author{
C.M. Cepeda-Jiménez, O.A. Ruano, M. Carsí, F. Carreño
}

Department of Physical Metallurgy, CENIM, CSIC, Av. Gregorio del Amo 8, 28040

Madrid, Spain

\begin{abstract}
The forming behaviour of an Al-Cu-Mg alloy (Al 2024-T351) has been studied by processing maps and microstructural characterization. Torsion tests were conducted in the range 278 to $467^{\circ} \mathrm{C}$, between 2.1 and $25.6 \mathrm{~s}^{-1}$. Stress-strain curves obtained from the experiment data were fitted using the Garofalo equation to obtain the constitutive parameters, obtaining a stress exponent of 6.1 and an activation energy of $180 \mathrm{~kJ} / \mathrm{mol}$. Electron backscatter diffraction (EBSD) was employed to characterize the microtexture and microstructure, before and after torsion testing, to evaluate the microstructural changes and instability phenomena. A peak ductility of the Al 2024 alloy was found at about $400{ }^{\circ} \mathrm{C}$ at all strain rates considered. According to the processing maps and microstructure observation, the optimum hot deformation condition for the Al 2024 alloy is in the range $360-410{ }^{\circ} \mathrm{C}$ and $2.1-4.5 \mathrm{~s}^{-1}$. Under these favourable conditions a uniform and fine grain size is obtained by extended dynamic recovery (DRV), which leads to the formation of subgrain boundaries that progressively transform at large strains into new high angle grain boundaries.
\end{abstract}

Keywords: A: Electron backscatter diffraction-EBSD; A: Mechanical characterization; B: Aluminium alloys; C: Hot deformation; D: Recrystallization; D: Processing maps.

*Corresponding author. Tel.: +34 915538900 ext.217; fax: +34 915347425.

E-mail address: cm.cepeda@cenim.csic.es (C.M. Cepeda-Jiménez)

\section{Introduction}

Al 2024 is an age-hardenable aluminium alloy, which is widely used in automobile and aerospace industry due to its good properties like low density and good damage tolerance [1]. In addition, in the last years investigations have been performed in order to extend its use in airplanes by introducing it together with other materials (metallic and non-metallic) in multilayer laminate composite materials with outstanding damage tolerance [2-4]. 
These metallic materials are frequently processed by hot rolling or forging, generally at elevated temperatures [5], being necessary to optimize processing parameters for maximum efficiency and workability. Workability or easiness of hot deformation is usually defined as the amount of deformation that a material can undergo without cracking or reaching undesirable conditions at a given temperature and strain rate [6].

The processing-map technique has been widely used to understand the hot deformation of many materials [7-9], in terms of the various microstructural changes occurring at the different deformation conditions [10].

To construct the maps, it is necessary to start from a constitutive equation that relates the experimental variables, stress-temperature-strain rate, obtaining the fields where a particular deformation mechanism is dominant [11]. In this study, the analysis of the deformation behaviour of the alloy was conducted by means of the Garofalo equation. This equation gives the envelope of all possible power law equations along the strain rate range investigated. The Garofalo equation has the form [12]:

$$
\dot{\varepsilon}=A \exp \left(-\frac{Q}{R T}\right)[\sinh \alpha \sigma]^{n}
$$

where $A, \alpha$ and $n$ are material constants, $R$ is the gas constant and $T$ is the temperature. The parameters of the Garofalo equation, $A, Q, n, \alpha$, can be determined by a non-linear method, that allows an automatic calculation, involving an algorithm specifically developed for the treatment of this equation. The adjustment and statistical treatment of this equation was described elsewhere [13,14].

In this work, torsion tests were conducted at various temperatures and strain rates. The torsion test has been widely used for evaluating the forming behaviour of materials at elevated temperatures [15]. Torsion testing offers the possibility of obtaining large deformations without the occurrence of plastic instability, under conditions simulating those encountered in industrial forming processes, such as hot rolling [16]. Accordingly, using torsion data, the parameters of the Garofalo equation were calculated and simulation of the forming process was conducted using processing maps.

Processing maps were plotted based on the dynamic materials modelling (DMM) [17], which considers the workpiece as a power dissipator [7]. The high temperature forming of metals can be analyzed by means of the supplied power to the material, $\mathrm{P}$, that can be divided in two terms:

$$
P=\sigma \dot{\varepsilon}=\int_{0}^{\dot{\varepsilon}} \sigma \mathrm{d} \dot{\varepsilon}+\int_{0}^{\sigma} \dot{\varepsilon} \mathrm{d} \sigma
$$

or $\mathrm{P}=\mathrm{G}+\mathrm{J}$, where $\mathrm{G}$, the dissipator content, represents the power dissipated by plastic work without changing the internal structure, most of which is converted into 
viscoplastic heat; and $\mathrm{J}$, the dissipator co-content, is related to the power dissipated by metallurgical processes, such as recovery, recrystallization, phase transformation, as well as damage of the material [17]. A relation of efficiency factors for $\mathrm{G}$ and $\mathrm{J}, \eta_{\mathrm{G}}$ and $\eta_{\mathrm{J}}$, can be obtained by diving Eq. (2) by the supplied energy:

$$
1=\eta_{\mathrm{G}}+\eta_{\mathrm{J}}
$$

Since the forming process of alloy implies changes in the internal structure, it is more interesting to study the term $\eta_{J}$ which is defined by the relation:

$$
\eta_{\mathrm{J}}=\frac{1}{\sigma \dot{\varepsilon}} \int_{0}^{\sigma} \dot{\varepsilon} \mathrm{d} \sigma(4)
$$

The resolution of this equation would be extremely difficult if the power law is used. This difficulty is avoided by the use of the Garofalo equation that is continuous and defined along the entire range of working strain rate. The following relation is obtained substituting Eq. (1) into Eq. (4):

$$
\eta_{\mathrm{J}}=\frac{1}{\sigma \dot{\varepsilon}} \int_{0}^{\sigma} A \exp \left(-\frac{\mathrm{Q}}{\mathrm{RT}}\right) \sinh (\alpha \sigma)^{\mathrm{n}} \mathrm{d} \sigma(5)
$$

This parameter and its variation with temperature and strain rate form the basis for construction of maps of constant forming efficiency contours.

In addition, once the maximum efficiency region is determined, it is necessary to locate the maximum stability region for the forming process. Different instability criteria have been formulated to identify the regions of flow instabilities and in this work we used the most common, the Lyapunov criteria [11,18-20].

Thermodynamically, the stability is understood as the state where the system evolves continuously diminishing the total energy. In engineering design, the control of the supplied and the dissipated energy is carried out by means of two variables. One is the entropy, $\mathrm{S}$, whose variation is defined as:

$$
\dot{S}=\left(\frac{\delta P}{\delta T}\right)
$$

The other variable is the efficiency $\eta=\mathrm{J} / \mathrm{G}$ that gives the dissipation rate. This variable can be substituted under certain conditions by the strain rate sensitivity, $m$ [19]. Thus, in this work the two Lyapunov stability criteria are given as:

$$
\mathrm{L}_{1}=\left(\frac{\delta m}{\delta \ln \dot{\varepsilon}}\right)_{\sigma}<0
$$

and

$$
\mathrm{L}_{2}=\left(\frac{\delta S}{\delta \ln \dot{\varepsilon}}\right)_{\sigma}<0
$$

Typical signatures of instability are shear band formation, flow localization, formation of cavities, breaking of particles, etc. [21-27]. 
The combination of the efficiency of power dissipation map and the instability map is the basis of a processing map, which could be used for correlating different regions where individual microstructural processes occur with processing variables [28]. Complementary microstructural characterization thus plays a vital role in understanding the deformation mechanisms associated with a specific regime, and in this study it has been extensively analyzed by the electron backscatter diffraction technique (EBSD).

Therefore, the aim of the present investigation is to study the high-temperature behaviour of an Al 2024 alloy using the analysis of hot torsion curves by the Garofalo constitutive equation and processing maps to determine the optimum hot deformation conditions. Characterization of the developed microstructure is also an important aim.

\section{Experimental procedure}

The aluminium alloy used in the present study was a rolled Al 2024-T351 plate of $12 \mathrm{~mm}$ in thickness. The composition in weight percentage of the alloy is $4.43 \% \mathrm{Cu}$, $1.33 \mathrm{Mg}, 0.04 \mathrm{Zn}, 0.62 \mathrm{Mn}, 0.17 \mathrm{Si}, 0.01 \mathrm{Ni}, 0.28 \mathrm{Fe}, 0.02 \mathrm{Cr}, 0.05 \mathrm{Ti}$, balanced Al.

Hot torsion tests were carried out on a computer-controlled and hydraulically powered torsion machine with the ends of the sample axially fixed. The hot torsion machine, SETARAM 7MN, has been described elsewhere [15]. The torsion samples were machined so that the gauge length coincided with the plate rolling direction. Samples $17 \mathrm{~mm}$ long and $3 \mathrm{~mm}$ radius in the gauge zone were torsioned to fracture at constant temperature and strain rate. In this study, hot torsion temperatures were selected between 278 and $467^{\circ} \mathrm{C}$, and four strain-rates $(\dot{\varepsilon})$ between 2.1 and $25.6 \mathrm{~s}^{-1}$ were considered. Then, Al 2024 samples were solutioned at $467^{\circ} \mathrm{C}$ for $10 \mathrm{~min}$ and hold for 15 min for microstructural stabilization, and afterwards, they were cooled in $2 \mathrm{~min}$ to testing temperature and tested to failure. The range of deformation parameters of the torsion test ( $\mathrm{T}$ and $\dot{\varepsilon}$ ) covered the conditions used during hot rolling of multilayer materials containing this aluminium alloy [2-4]. Furthermore, the recommended hot working temperature range for most aluminium alloys is given between $260-480^{\circ} \mathrm{C}$ [6].

The samples were introduced in a silica tube with an argon inlet, to ensure protection against oxidation, and heated by a high frequency induction furnace. The temperature during the torsion test was measured by a two-colour pyrometer. Immediately after fracture, the samples were water quenched in less than $0.5 \mathrm{~s}$ in order to retain the deformation microstructure, especially the grain size.

The torsion tests provided directly the curves of torque, $\Gamma$, versus number of turns N. The effective stress $(\sigma)$, the effective strain $(\varepsilon)$ and the strain rate $(\dot{\varepsilon})$ were calculated by means of the following relationships $[29,30]$ : 


$$
\sigma=\frac{\Gamma \sqrt{3}}{2 \pi \mathrm{R}^{3}}(3+m+\theta) \quad \varepsilon=\frac{2 \pi \mathrm{RN}}{\mathrm{L} \sqrt{3}} \quad \dot{\varepsilon}=\frac{2 \pi \mathrm{R} \dot{\mathrm{N}}}{\mathrm{L} \sqrt{3}}
$$

where $\mathrm{R}$ is the sample radius, $\mathrm{L}$ is the gauge length, $m$ is the strain rate sensitivity and $\theta$ is the work hardening exponent:

$$
m=\left.\frac{\partial \ln \Gamma}{\partial \ln \dot{\varepsilon}}\right|_{\varepsilon, T} \quad \theta=\left.\frac{\partial \ln \Gamma}{\partial \ln \varepsilon}\right|_{\dot{\varepsilon}, T}
$$

For the data analysis the peak stresses were taken into account, being $\theta=0$. In addition $m$ was taken equal to 0.13 , which corresponds to the average value calculated from all torsion data.

Electron backscatter diffraction (EBSD) was employed in the present investigation to characterize the microtexture and microstructure of the $\mathrm{Al} 2024$ alloy tested by hot torsion. The samples for EBSD observation were prepared on sections parallel to the torsion axis at a distance of $0.7 \mathrm{R}$, with $\mathrm{R}$ being the radius of the gauge length as illustrated in Fig. 1. The EBSD scans were carried out at the centre of the observation surface. The initial grain size of the alloy for each torsion condition was determined in the non-deformed region (head) of the torsion samples.

Orientation maps were performed by EBSD in a scanning electron microscope (SEM) JEOL JSM 6500F, with a fully automatic EBSD attachment, HKL Technology, operating at an accelerating voltage and a working distance of $20 \mathrm{kV}$ and $15 \mathrm{~mm}$, respectively. The corresponding data processing was carried out using HKL Channel 5 software. The area mapping for the torsion tested samples was $430 \times 343 \mu \mathrm{m}$ with a step size of $0.25 \mu \mathrm{m}$. The low angle grain boundary (LAB) was defined by a misorientation between adjacent grains of $2^{\circ}<\theta<15^{\circ}$, and the high angle grain boundary (HAB) was defined by $\theta>15^{\circ}$. The HABs and LABs are shown as black and white lines respectively on the maps. Specimens were mechanically polished and then electropolished in a $30 \%$ nitric acid solution in methanol at $-28^{\circ} \mathrm{C}$ and $15 \mathrm{~V}$.

\section{Results}

\subsection{Torsion tests}

Figure 2 shows the results of the torsion tests to fracture carried out at temperatures ranged between 278 and $467^{\circ} \mathrm{C}$ and at strain rates between 2.1 (Fig. 2a) and $25.6 \mathrm{~s}^{-1}$ (Fig. 2d). Every curve shows a rapid increase in the stress to a peak value $\left(\sigma_{\mathrm{p}}\right)$, followed by different softening degrees until the rupture of the sample at all strain rates, as a consequence of dynamic microstructural changes. At a constant strain rate, the strain corresponding to the peak stress increases slightly with the decrease in deformation 
temperature. In addition, the flow stress decreases clearly with temperature at a given strain rate, while an increase in the strain rate at a given deformation temperature, especially at the lowest test temperatures of 315 and $278^{\circ} \mathrm{C}$, has little influence on the flow stress. At the lowest temperatures of 315 and $278^{\circ} \mathrm{C}$ and strain rates higher than 9.6 $\mathrm{s}^{-1}$ (Fig. 2c and 2d), the stress-strain curves show considerable softening after reaching the peak. However, at the higher temperatures, the flow behaviour is clearly different. At temperatures higher than $360^{\circ} \mathrm{C}$ and clearly at low strain rates of 2.1-4.5 s ${ }^{-1}$ (Fig. 2a and $2 \mathrm{~b}$ ), the initial work hardening region is reduced and nearly flat stress-strain curves are observed after a small initial peak stress, which are indicative of steady-state flow behaviour.

On the other hand, the curves of the figure clearly show that the strain to failure increases with decreasing strain rate at all test temperatures. Figure 3 shows more clearly the relation-ship between elongation to failure, $\varepsilon_{F}$, and temperature at various strain rates. It can be seen that both strain rate and temperature influence the ductility. For a given temperature, the torsional ductility generally decreases with an increase in strain rate. In addition, the general trend is that, for a given strain rate, a maximum in ductility is observed at about $400^{\circ} \mathrm{C}$, especially at low strain rates. It is worth noting the decrease in ductility at the highest test temperature of $467^{\circ} \mathrm{C}$ at the lowest strain rates.

\subsection{Processing maps}

The Garofalo equation (1) has been used to fit the experimental torsion data and determine the constitutive parameters. Accordingly, the optimal solution of the parameters of the Garofalo equation obtained in this study is the following:

$$
\dot{\varepsilon} \exp (179.7 \mathrm{k} \mathrm{J} / \mathrm{mol} \mathrm{RT})=4.16876 \times 10^{13}(\sinh (0.0103 \sigma))^{6.1}
$$

For this alloy, the apparent stress exponent is $n_{a p}=6.1$ and the activation energy for deformation is $\mathrm{Q}_{\mathrm{ap}}=180 \mathrm{~kJ} / \mathrm{mol}$. The $n_{a p}$ value is lower than that consistent with a slip creep mechanism controlled by dislocation climb at constant substructure, $n=8$ [31], and the activation energy is higher than the value of $\mathrm{Q}_{\mathrm{L}}=142 \mathrm{~kJ} / \mathrm{mol}$ measured for lattice self-diffusion of aluminium [32]. This is attributed to microstructural coarsening as will be discussed below.

A representation based on the Zener-Hollomon parameter, $Z=\dot{\varepsilon} \exp (Q / R T)$, as a function of $\sinh (\alpha \sigma)$ is usually performed to prove the goodness of the fit by the nonlinear method used to obtain the parameters of the Garofalo equation. This representation, given in Fig. 4, involves combination of original variables, $\dot{\varepsilon}$ and $T$, into $Z$. The points given in the figure are obtained by means of the experimental data using the parameters $A, Q, n, \alpha$, obtained from the non-linear method. These points fall close 
to the central line given in this figure. This line corresponds to the best fit and the two adjacent lines defining the $95 \%$ confidence band for the best fit. Thus, as the points fall between the $95 \%$ confidence band, and the correlation coefficient of the final solution is $r=0.996$, the fitting has good accuracy and can be considered satisfactory [33].

In addition, the flow stress data have been analyzed using the processing map technique described in the introduction to evaluate the behaviour of the Al 2024 alloy during hot deformation.

Fig. 5 shows a two-dimensional map of constant forming efficiency contours, which correspond to a projection on a $\dot{\varepsilon}, T$ plane. The numbers against each contour represent efficiency of power dissipation, $\eta_{\mathrm{J}}$, which characterize the rate of microstructure evolution in the hot working process [28]. The values of $\eta_{J}$ are between 6 and $13 \%$ in the figure. It is shown that the efficiency increases for decreasing strain rates at constant temperature. An efficiency range of $12-13 \%$ is spread from $360{ }^{\circ} \mathrm{C}$ to $467{ }^{\circ} \mathrm{C}$ at low strain rates, while it decreases to $9 \%$ at high strain rates over the same temperature range, and 6-7\% at lower temperatures. It is worth noting that the flow curves corresponding to the maximum efficiency exhibited steady state behaviour (Fig. $2 a$ and $b)$.

Once the maximum efficiency region is determined, it is necessary to locate the maximum stability region for the forming process. The representation of the $1^{\text {st }}$ and $2^{\text {nd }}$ Lyapunov criterion is given in Figs. 6 and 7, respectively. These figures are two dimensional representations of the stability criteria as a function of strain rate and temperature. The most stable region in both figures corresponds to the most negative values of the Lyapunov function. Fig. 6 shows a stability band between 300 and $450^{\circ} \mathrm{C}$, being optimum at approximately $400^{\circ} \mathrm{C}$ for a strain rate of $\sim 5 \mathrm{~s}^{-1}(\ln 5=1.6)$, between the level lines for -0.007 . Similarly, Fig. 7 shows that the most stable region in this figure is that comprised between the level lines for -0.25 to -0.23 . This region is strain rate dependent and optimum stability values between 350 and $400^{\circ} \mathrm{C}$ are obtained for about $4.5 \mathrm{~s}^{-1}$. It presents thus the lower chance of crack appearance and is recommended for a stable forming process.

\subsection{Microstructure of the deformed samples}

In order to understand the effect of torsion deformation on the structure and correlate with the processing maps, the microstructure of the as-received and torsion tested A1 2024 alloy was evaluated.

Fig. 8 shows a backscattered electron micrograph of the as-received Al 2024-T351 alloy (Fig. 8a) and its corresponding EBSD map (Fig. 8b) in the LT orientation 
(longitudinal-transversal). In addition, Fig. $8 \mathrm{c}$ and $\mathrm{d}$ show the microstructures corresponding to the undeformed part (head) of a torsion sample soaked at $467^{\circ} \mathrm{C}$ for 15 min and torsion tested at $467^{\circ} \mathrm{C}$ plus water quenched (Fig. 8c), or soaked at $467^{\circ} \mathrm{C}$ and torsion tested at $278^{\circ} \mathrm{C}$ (Fig. 8d). The EBSD maps have been colour coded according to the inverse pole figure (IPF) shown in the inset, and the colours represent the crystallographic orientations parallel to the normal direction (ND) for the rolled asreceived Al 2024 alloy (Fig. 8b), and to orientations parallel to the characterization plane normal, shown in Fig. 1, for the torsion tested samples (Fig. 8c-d).

The microstructure of the as-received Al 2024-T351 alloy (Fig. 8a and b) consists of recrystallized grains, with spacing between high-angle grain boundaries (HABs) in the normal to rolling direction of about $7.4 \mu \mathrm{m}$. The fraction of high-angle grain boundaries $\left(f_{\mathrm{HAB}}\right)$ was $92 \%$ and the $\{111\}$ pole figure of Fig. $8 \mathrm{~b}$ shows that the as-received material was only weakly textured, containing grains of a wide range of orientations. In addition, large insoluble iron-rich intermetallic particles and partially soluble constituent particles were observed to be randomly distributed, and they are ranged in size from 0.5 to $5 \mu \mathrm{m}$ (Fig. 8a). Previous works on this alloy [34,35] have reported three types of intermetallic particles, $\mathrm{Al}_{7} \mathrm{Cu}_{2} \mathrm{Fe},(\mathrm{Al}, \mathrm{Cu})_{6} \mathrm{Fe}$ and $\mathrm{Mg}_{2} \mathrm{Si}$.

Fig. 8c and Fig. 8d show the EBSD maps of the undeformed head of torsion samples tested under different conditions. The shear direction in the EBSD maps is vertical and the radial direction is normal to the page. Both EBSD maps show a very large recrystallized grain size elongated in the original rolling direction $(\sim 40 \mu \mathrm{m}$ in thickness). The large grain growth observed in the undeformed head of the torsion samples is produced during static annealing at $467^{\circ} \mathrm{C}$ [36], and the grain size does not change during the subsequent cooling to other test temperatures (Fig. 8d).

Fig. 9 shows EBSD maps and $\{111\}$ pole figures of tested samples at $4.5 \mathrm{~s}^{-1}$ and different temperatures. This strain rate has been selected because the flow curves at the various temperatures, Fig. 2b, show the different deformation stages of this material, i.e, samples tested at this $\dot{\varepsilon}$ and high temperature present similar steady-state flow curves than those tested at lower $\dot{\varepsilon}$ (Fig.2a); and on the contrary, samples tested at $4.5 \mathrm{~s}^{-1}$ and low temperature presents similar low ductility, peak stress and flow softening than samples tested at higher $\dot{\varepsilon}$ (Fig. 2c and d).

In general, the EBSD maps for all torsion test conditions of Fig. 9 have a common microstructure constituted by the recrystallized grains, observed in the undeformed head, elongated around the torsion axis in a spiral. In addition, a substructure is observed inside the elongated grains, which is characteristic of dynamic recovery (DRV) during deformation. The microstructure corresponding to the Al 2024 tested at 
$467^{\circ} \mathrm{C}$ (Fig. 9a) consists of chains of equiaxed or slightly elongated subgrains developed in the vicinities of initial grain boundaries. The average subgrain size developed is very heterogeneous, and the fraction of high-angle boundaries, $f_{\mathrm{HABs}}$, and the mean correlated misorientation, $\bar{\theta}_{c}$, is $44 \%$ and $19^{\circ}$ respectively. These values are relatively low as a consequence of a microstructure characterized by a high density of strain-induced LABs.

With the decrease of test temperature to $408^{\circ} \mathrm{C}$ (Fig. 9b) and $360^{\circ} \mathrm{C}$ (Fig. 9c), the original HABs and the new deformation-induced low-angle boundaries rotate towards the shear direction, as a consequence of higher $\varepsilon_{\mathrm{F}}$ (Fig. 2b and 3). Furthermore, new finer equiaxed (sub)grains surrounded by high-angle grain boundaries are developed inside the initial grains, as a consequence of the higher stress during the torsion test with respect to $467^{\circ} \mathrm{C}$. Therefore, since it is widely accepted that the (sub)grain size (L) depends on the stress $(\sigma)$ [37] such that $L \propto 1 / \sigma$, the mechanical behavior and the lower (sub)grain size obtained at lower test temperature is the expected. In addition, while the subgrain size is relatively insensitive to strain and is determined by the stress, the misorientation across subgrain walls increase with increasing deformation degree [38]. Accordingly, at $408^{\circ} \mathrm{C}$ and $4.5 \mathrm{~s}^{-1}$ (Fig. 9b) the microstructure is still poorly misoriented with a $f_{\mathrm{HAB}}=19 \%$ and $\left(\bar{\theta}_{\mathrm{c}}\right)=10^{\circ}$. However, at $360^{\circ} \mathrm{C}$ (Fig. $\left.9 \mathrm{c}\right)$ the average (sub)grain size is finer with respect to higher test temperature due to higher stress, and $f_{\mathrm{HAB}}$ and $\left(\bar{\theta}_{\mathrm{c}}\right)$ increase to $41 \%$ and $19^{\circ}$, respectively. It is clearly seen in Fig. 9c that the formation of new grains takes place along the original grain boundaries from deformation-induced LABs with increasing misorientations [39].

Finally, the torsion sample tested at $278^{\circ} \mathrm{C}$ (Fig. 9d) exhibits the large initial grains, with an apparent work hardened microstructure and poorly developed deformationinduced LABs. Furthermore, the $f_{\mathrm{HAB}}$ for this torsion test condition is drastically reduced to $f_{\mathrm{HAB}}=9 \%$ and $\left(\bar{\theta}_{\mathrm{c}}\right)=7^{\circ}$ which is due to the high amount of low angle boundaries and dislocation structures within the grains.

The corresponding textures as $\{111\}$ pole figures are also given in Fig. 9. FCC metals like aluminium, with high stacking fault energy, present stable torsion textures consisting of a strong $\{h \mathrm{kl}\}<110>\mathrm{B}$ fibre and a less strong $\{111\}<\mathrm{uvw}>$ A fibre [40] (Fig. 9e), i.e., there is a strong tendency for the slip direction to become aligned with the shear direction. In aluminium, the ideal $\{100\}<110>$ (C orientation) and $\{112\}<110>$ (B orientation) components are normally positions of high orientation density on the $\mathrm{B}$ fibre [41].

In general, the textures corresponding to all temperatures (Fig. 9) show the development of the commonly observed shear texture components, i.e, A $\{111\}<110>$, 
B $\{112\}<110>$ and $\mathrm{C}\{001\}<110>$. At $467^{\circ} \mathrm{C}$ (Fig.9a) and $278^{\circ} \mathrm{C}$ (Fig.9d), which showed lower deformation (Fig. 2b), the main texture component is B orientation $\left(\{112\}<110>\right.$ ), while at 408 (Fig. 9b) and $360^{\circ} \mathrm{C}$ (Fig. 9c) the $\mathrm{C}$ texture component $(\{001\}<110>)$ is clearly developed. These results are in agreement with previous works on torsion tests of aluminium alloys [42-45], where the A component $\{111\}<110>$ was found to decrease rapidly with strain, being replaced by the $\mathrm{C}\{001\}<110>$ and the $\mathrm{B}$ $\{112\}<110>$ components at large strains. In these works, the $\mathrm{C}$ component was found to be weak at small strains, and to increase continuously up to strains of about 5, where the intensity of this component was seen to have values of 9 to 10 times random. On the contrary, the B orientation decreased to a value of 3 times random. On the other hand, also it has been reported [43] a faster decrease in the intensity of the $\mathrm{C}$ component and increase of the $\mathrm{B}$ component with increasing stress. This also can explain the higher intensity of the B component $\{112\}<110>$ for the samples tested at lower test temperatures in the present study.

Finally, Fig. 10 shows the corresponding backscattered electron micrographs to the EBSD maps of Fig. 9. At $408^{\circ} \mathrm{C}$ (Fig. 10b) incipient precipitation occurs during cooling to test temperature and a precipitate distribution fine and homogenous can be observed. The decrease in test temperature to $360^{\circ} \mathrm{C}$ (Fig. 10c) and $278^{\circ} \mathrm{C}$ (Fig. 10d) leads to large amount of precipitation, especially at the grain boundaries. In contrast, at the highest test temperature of $467^{\circ} \mathrm{C}$ (Fig.10a) only the initial large insoluble intermetallic particles are observed on the aluminium matrix, being the alloying elements in solid solution.

\section{Discussion}

In this work, the aeronautical Al 2024 alloy was deformed by hot torsion after solution treatment, in a temperature range of $278-467^{\circ} \mathrm{C}$ and $2.1-25.6 \mathrm{~s}^{-1}$ strain rate, and processing maps were obtained. The microstructures of the torsioned samples were characterized by EBSD in order to correlate with the processing maps.

The plastic elongation to failure $\left(\varepsilon_{\mathrm{F}}\right)$ measured at two different strain rates, 4.5 and $25.6 \mathrm{~s}^{-1}$ as a function of temperature is depicted in Fig. 11a and 11b, respectively. Also, the efficiency of power dissipation $\left(\eta_{\mathrm{J}}\right)$ and the instability parameter according to the $2^{\text {nd }}$ Lyapunov criterion have been included in Fig. 11. The intersection region for maximum stability defined by the two Lyapunov criteria (Figs. 6 and 7) together with the maximum efficiency (Fig. 5) and ductility (Fig.3) should give the best conditions for the forming process [46].

At low strain rate $\left(4.5 \mathrm{~s}^{-1}\right.$, Fig. 11a), the ductility shows a clear peak of maximum ductility at about $400^{\circ} \mathrm{C}$. In addition, the efficiency increases progressively with 
temperature, although above $400^{\circ} \mathrm{C}$ this enhancement is more moderate. According to Prasad and Srinivasan [7,47], the domains of high efficiency and ductility can be associated with dynamic restoration mechanisms, namely dynamic recrystallization (DRX) and dynamic recovery (DRV) which improve the workability of the material.

As commented, the efficiency variation in Fig. 11a exhibits a monotonic increase with temperature, even though the ductility is lower at the higher temperature of $467^{\circ} \mathrm{C}$. High efficiency with less ductility and high instability at high temperature can be associated with the presence of solid solution. Previous DSC studies on the precipitation phenomena in the Al 2024 alloy [48-50] demonstrated that precipitation occurs by cooling below $430^{\circ} \mathrm{C}$. Accordingly, we can assume that the following microstructural changes occur during the homogenization treatment and during the hot-torsion tests: i) a prolonged homogenization for $30 \mathrm{~min}$ at $467^{\circ} \mathrm{C}$, as performed in this study, largely removes $\theta\left(\mathrm{CuAl}_{2}\right)$ and $\mathrm{S}\left(\mathrm{CuMgAl}_{2}\right)$ precipitates, bringing copper and magnesium atoms into solid solution [49]; ii) the subsequent cooling to torsion test temperatures together with deformation produces that very fine particles start to precipitate dynamically at high torsion temperatures $\left(408\right.$ and $\left.360^{\circ} \mathrm{C}\right)$ from solid solution; iii) at lower testing temperatures $\left(315\right.$ and $\left.278^{\circ} \mathrm{C}\right)$, a considerable amount of precipitation must occur as a result of the cooling to the test temperature and deformation (dynamic precipitation) (Fig. 10).

Accordingly to this precipitation sequence, the presence of solid solution strengthening at $467^{\circ} \mathrm{C}$ adversely affect the climb controlled DRV process [51] and shift the optimum deformation condition for DRV to lower temperatures (Fig. 11a). It has been widely reported by different authors that any dislocation moving through a solid solution will encounter friction drag, raising the energy required for movement [51]. In this way, Charit et al [52] reported that alloying elements in solid solution can diffuse to dislocation cores forming a saturated atmosphere of solute, imposing a drag force. Furthermore, N. Jin et al. [51] demonstrated that recovery processes are also hindered by a higher solute atom vacancy binding energy which effectively reduces the number of vacancies available for dislocation climb whilst the misfit strain effectively raises the dislocation density, and both processes contributing to an increase in activation energy for hot deformation. Furthermore, it also has been reported that copper (present in the alloy considered in this study) is more effective than magnesium in inhibiting dynamic recovery [53], taking into account that magnesium has long been known to inhibit dynamic recovery in aluminium alloys [54,55]. For $\mathrm{Mg}$, the decrease in dynamic recovery has often been associated with a reduction in the stacking fault energy (SFE) [53]. However, although copper increases the SFE [56], when compared at the same atomic concentration of $\mathrm{Mg}$, it has been found to have a greater influence on both solid 
solution strengthening and reducing the rate of recovery, at least after deformation to conventional strains [57]. In addition, Huang et al [53] reported that between the methods available for limiting grain coarsening, such as the introduction of secondphase particles to pin boundary migration, or the use of solute to inhibit recovery, the use of solute is arguably the most effective approach in aluminium alloys. Therefore, at the sight of experimental evidences, it is our contention that the decrease in ductility at high temperature is due to the presence of solid solution.

On the other hand, generally, the efficiency values associated with mechanisms such as DRX are about 35-45\% [7,47,58] and 20-30\% for DRV [7]. The lesser efficiency values for DRV are due to the less effective energy dissipation through dislocation annihilation compared to DRX in which the migration of interfaces also contribute to annihilation of a large number of dislocations [10]. In this study the maximum efficiency value is about $14 \%$, being close to values reported for DRV.

On the other hand, the deformation conditions of minimum hot ductility (i.e. at 467 ${ }^{\circ} \mathrm{C}$ and $278-315^{\circ} \mathrm{C}$ ) in Fig. 11a lie in the maximum instability regions, taking into account that the most negative value of the instability parameter corresponds to safer forming regions. As commented before, the minimum ductility observed at $467^{\circ} \mathrm{C}$ is attributed to the presence of solid solution. However, at low test temperature the instability increase is mainly due to the monotonic increment of precipitates with diminishing testing temperature. Lowering the temperature to $278^{\circ} \mathrm{C}$ increases precipitation potential (Fig. 10d), changing dramatically recovery processes. Microstructure examination of the sample deformed at $4.5 \mathrm{~s}^{-1}$ and $278^{\circ} \mathrm{C}$ (Fig. 9d and 10d) reveals that the softening observed in the flow stress curves (Fig. 2) at high $\dot{\varepsilon}$ and low $\mathrm{T}$ is due to flow instability, as observed in the processing maps, Figs. 6, 7, and 11, caused by severe shear flow localization and dynamic precipitation and coarsening (Fig. 10d). The work hardened microstructure observed at $278^{\circ} \mathrm{C}$ (Fig. 9d) is attributed to the presence of undeformed coarsened precipitates (Fig. 10d), producing large local strain gradients around precipitates [59], that lead to high dislocation density and fine subgrain size during hot deformation. Accordingly, this work-hardened microstructure with incipient formation of subgrains showed very low mean misorientation $\left(7^{\circ}\right)$. In addition, the energy required to nucleate coarse voids in the grain interior is significantly reduced due to coarse precipitate formation in the period lasting between the solution treatment and the torsion testing, together with additional coarsening by deformation, thus decreasing its ductility (Fig. 3) [60]. Thus, during the hot forging process, the reinforcements play an important role inducing plastic instability at low temperatures.

At $25.6 \mathrm{~s}^{-1}$ (Fig. 11b) the ductility is very low and remains almost constant with temperature while the efficiency exhibits considerable increase with temperature. In 
addition, an increase in instability and a decrease in $\eta_{\mathrm{J}}$ is observed at low temperatures at this high strain rate. It is our contention that at high strain rate at all temperatures, strain incompatibility between the aluminium matrix and dynamic coarsened precipitates is a possible source for void formation due to a strain concentration factor near precipitates $[61,62]$, diminishing drastically the ductility. Therefore, according to Fig. 11a and $11 \mathrm{~b}$, lower temperatures than $350^{\circ} \mathrm{C}$ and high strain rates at any temperature should be avoided in the material processing.

Fig. 12 shows EBSD maps corresponding to the sample deformed at $408{ }^{\circ} \mathrm{C}$ and 2.1 $\mathrm{s}^{-1}$, having the highest ductility (Fig. 3), high efficiency (Fig. 5) and low instability (Figs. 6 and 7). This microstructure shows typical features of dynamic recovery. As commented, high DRV degree is a beneficial process in hot deformation as it gives good intrinsic workability by simultaneous softening and development of a fine and misoriented microstructure [63]. The average grain size of the sample deformed at 408 ${ }^{\circ} \mathrm{C}$ decreases to $1.9 \mu \mathrm{m}$, and the $f_{\mathrm{HAB}}$ and $\bar{\theta}_{\mathrm{c}}$ are considerably increased to $54 \%$ and $23^{\circ}$, respectively. In Fig. 12b, which corresponds to a Kikuchi band contrast map, where the high-angle boundaries are painted in black and the low-angle ones are green, it can be seen the very dense HABs network. The high strain experimented at this test condition ( $\varepsilon \sim 8.2$, Fig. 3) leads to the gradual build-up of higher misorientation between the neighbouring subgrains. The uniform and fine grain size thus can be attributed to the occurrence of dynamic recovery, which leads to the formation of subgrain boundaries which progressively transform at large strains into new high angle grain boundaries. Furthermore, at this temperature $\left(408^{\circ} \mathrm{C}\right)$ based in DSC results [64] still dissolving alloying elements and incipient fine precipitates are present, which also contribute by a pinning effect, together with the high temperature, to this transformation of LABs into HABs.

On the other hand, for this test condition the main torsion texture components (B$\{112\}<110>$ and $C-\{001\}<110>$ ) are clearly developed, due to the nature of the crystallographic rotation field in simple shear and the high ductility.

Finally, the fitting of the experimental data by the Garofalo equation gives an apparent activation energy value of $180 \mathrm{~kJ} / \mathrm{mol}$. This value is higher than that for selfdiffusion in pure aluminium $\left(\mathrm{Q}_{\mathrm{L}}=142 \mathrm{~kJ} / \mathrm{mol}\right.$ [32]). On the other hand, the $n_{a p}$ value is lower than that consistent with a slip creep mechanism controlled by dislocation climb at constant substructure, $n=8$ [31]. Thus, although the deformation behaviour during hot forming of the Al 2024 alloy is consistent with this mechanism, the high activation energy and low $n_{a p}$ values obtained are attributed to microstructural changes occurring at the various torsion test conditions. Accordingly, at high temperature the flow stress is decreased by precipitate dissolution while at lower test temperatures the stress is 
increased by dynamic precipitation, coalescence and particle coarsening, which, additionally, favour void and crack nucleation.

In summary, the hot deformation of the Al 2024 alloy estimated by the efficiency, ductility and instability parameters is determined by the microstructure evolution during deformation, being optimum when high dynamic recovery degree is obtained. A forming temperature interval of $360-410^{\circ} \mathrm{C}$ at $2.1-4.5 \mathrm{~s}^{-1}$ is recommended.

\section{Conclusions}

The hot deformation behaviour of the Al 2024 alloy was analyzed by torsion testing, constitutive equations and processing maps. EBSD was employed to characterize the microstructure and its correlation with processing maps. The main conclusions of this study are as follows:

1. The high temperature data can be predicted by means of a Garofalo equation with a stress exponent of 6.1 and an activation energy for deformation of 180 $\mathrm{kJ} / \mathrm{mol}$ (being $\mathrm{Q}_{\mathrm{L}}=142 \mathrm{~kJ} / \mathrm{mol}$ ), corresponding to a mechanism of constantsubstructure slip creep $(n=8)$, but experiencing microstructural changes due to the effect of precipitates at different temperatures.

2. The working regime for the forming of the alloy has been established by determination of maximum efficiency and stability zones. A forming temperature range of $360-410^{\circ} \mathrm{C}$ and strain rates of $2.1-4.5 \mathrm{~s}^{-1}$ is recommended having high values of efficiency $\left(\eta_{\mathrm{J}}=13 \%\right)$. In such conditions of $\mathrm{T}$ and $\dot{\varepsilon}$ the material exhibits dynamic extended recovery, as revealed by EBSD observations.

3. The decrease of test temperatures to $278-315^{\circ} \mathrm{C}$, especially at high strain rates, increases the risk of flow instability, due to flow localization by dynamic precipitation, coalescence and particle coarsening. Coarsened precipitates favour crack nucleation, thus decreasing the ductility.

4. The increase of test temperature to $467^{\circ} \mathrm{C}$ at all strain rates leads to limited ductility due to the presence of alloying elements in solid solution, which hinder dislocation movement and dynamic recovery processes.

\section{Acknowledgements}

Financial support from CICYT (Project MAT2009-14452) is gratefully acknowledged. We also thank F.F. González-Rodríguez for assistance with the hot torsion tests. 


\section{References}

1. J.C. Malas, S. Venugopal, T. Seshacharyulu, Mater. Sci. Eng. A 368 (2004) 41-47.

2. C.M. Cepeda-Jiménez, R.C. Alderliesten, O.A. Ruano, F. Carreño, Compos. Sci. Technol. 69 (2009) 343-348.

3. C.M. Cepeda-Jiménez, M. Pozuelo, J.M. Garcia-Infanta, O.A. Ruano, F. Carreño, Metall. Mater. Trans A 40A (2009) 69-79.

4. C.M. Cepeda-Jiménez, P. Hidalgo, M. Pozuelo, O.A. Ruano, F. Carreño, Mater. Sci. Eng. A A527 (2010) 2579-2587.

5. N.S. Babu, S.B. Tiwari, B.N. Rao, Mater. Sci. Technol. 21 (2005) 976-984.

6. M. Gavgali, B. Aksakal, Mater. Sci. Eng. A 254 (1998) 189-199.

7. Y.V.R.K. Prasad, S. Sasidhara, Hot Working Guide: A compendium on Processing Maps, ASM International, Metals Park, OH, 1997.

8. M. Rajamuthamilselvan, S. Ramanathan, J. Alloy. Compd. 509 (2011) 948-952.

9. M.Mu, Z. Zhi-min, Z. Bao-hong, D.Jin, J. Alloy. Compd. 513 (2012) 112-117.

10. N. Srinivasan, Y.V.R.K. Prasad, P.R. Rao, Mater. Sci. Eng. A 476 (2008) 146-156.

11. M. Carsí, F. Peñalba, I. Rieiro, F. Zapiráin, O.A. Ruano, Z. Metallkd. 91 (2000) 1057-1062.

12. F. Garofalo, Fundamentals of Creep and Creeps Rupture in Metals, MacMillan, New York, 1965.

13. I. Rieiro, M. Carsí, F. Peñalba, Rev. Metal. Madrid, 32 (1996) 321-328.

14. I. Rieiro, M. Carsí, O.A. Ruano, Mater. Sci. Technol., 25 (2009) 995-1002.

15. M. Carsí, F. Peñalba, O.A. Ruano, O.D. Sherby, Metall. Mater. Trans. A 28 (1997) 1913-1920.

16. M. Ueki, S. Horie, T. Nakamura, J. Mater. Process. Technol. 11 (1985) 365-376.

17. Y.V.R.K. Prasad, H.L. Gegel, S.M. Doraivelu, J.C. Malas, J.T. Morgan, K.A. Lark, D.R. Barker, Metall. Trans. 15 A (1984) 1883-1892.

18. H.L. Gegel, J.C. Malas, S.M. Doraivelu, V.A. Shende, Modeling techniques used in forging process desing, in: Metals Handbook, ASM International, Metals Park, $\mathrm{OH}$, 1988, vol.14, pp.417-438.

19. J.M. Alexander, Mapping dynamic material behaviour, in: J.G. Lenard (ed), Modelling of hot deformation of steels, Springer-Verlag, Berlin, 1989, pp.105-115.

20. D. Samantaray, S. Mandal, A.K. Bahduri, Mater. Design 32 (2011) 716-722.

21. Y.V.R.K. Prasad, T. Seshacharyulu, Mater. Sci. Eng. A 243 (1998) 82-88.

22. S.L. Semiatin, V. Seetharaman, I. Weiss, Mater. Sci. Eng. A 263 (1999) 257-271. 
23. T. Seshacharyulu, S.C. Medeiros, J.T. Morgan, J.C. Malas, W.G. Frazier, Y.V.R.K. Prasad, Scripta Mater. 41 (1999) 283-288.

24. R.M. Miller, T.R. Bieler, S.L. Semiatin, Scripta Mater. 40 (1999) 1387-1393.

25. T. Seshacharayulu, S.C. Medeiros, J.T. Morgan, J.C. Malas, W.G. Frazier, Y.V.R.K. Prasad, Mater. Sci. Eng. A 279 (2000) 289-299.

26. S.L. Semiatin, T.R. Bieler, Acta Mater. 49 (2001) 3565-3573.

27. B.K. Raghunath, K. Raghukandan, R. Karthikeyan, K. Palanikumar, U.T.S. Pillai, R. Ashok Gandhi, J. Alloy. Compd. 509 (2011) 4992-4998.

28. M. Gang, L. Bolong, L. Hongmei, H. Hui, N. Zuoren, Mater. Sci. Eng. A 517 (2009) 132-137.

29. D.S. Fields Jr., W.A. Backofen, Proc. Am. Soc. Test. Mater. 57 (1957) 1259-1272.

30. M. Carsí, R. Allende, F. Peñalba, J.A. Jiménez, O.A. Ruano, Steel Res. Int. 75 (2004) 26-32.

31. O.D. Sherby, R.H. Klundt, A.K. Miller, Metal. Trans. A 8 (1977) 843-850.

32. H.J. Frost, M.F. Ashby, Deformation-Mechanism Maps, Pergamon Press, Oxford, U.K., 1982.

33. D.M. Bates, D.G. Watts, Non Linear Regression Analysis and its Applications, John Wiley \& Sons, New York, 1986.

34. C.E. Campbell, L.A. Bendersky, W.J. Boettinger, R. Ivester, Mater. Sci. Eng. A 430 (2006) 15-26.

35. Y. Xue, H. El Kadiri, M.F. Horstemeyer, J.B. Jordon, H. Weiland, Acta Mater. 55 (2007) 1975-1984.

36. J. Dennis, P.S. Bate, F.J. Humphreys, Acta Mater. 57 (2009) 4539-4547.

37. O.D. Sherby, P.M. Burke, Progress Mater. Sci. 13 (1968) 323-390.

38. M.R. Barnett, F. Montheillet, Acta Mater. 50 (2002) 2285-2296.

39. N. Dudova, A. Belyakov, T. Sakai, R. Kaibyshev, Acta Mater. 58 (2010) 36243632 .

40. A. Gholinia, P. Bate, P.B. Prangnell, Acta Mater. 50 (2002) 2121-2136.

41. G.R. Canova, U.F. Kocks, J.J. Jonas, Acta Metall. 32 (1984) 211-226.

42. F. Montheillet, M. Cohen, J.J. Jonas, Acta Metall. 32 (1984) 2077-2089.

43. J.K. Solberg, H.J. McQueen, N. Ryum, E. Nes, Phil. Mag. A 60 (1989) 447-471.

44. H.J. McQueen, J.K. Solberg, N. Ryum, E. Nes, Phil. Mag. A 60 (1989) 473-485.

45. T. Pettersen, E. Nes, Metall Mater Trans A 34 (2003) 2727-2736. 
46. M. Carsí, I. Rieiro, J.A. Jiménez, F. Peñalba, O.A. Ruano, J. Mater. Process. Technol. 143-144 (2003) 416-419.

47. N. Srinivasan, Y.V.R.K. Prasad, Mater. Sci. Technol. 8 (1992) 206-212.

48. B. Verlinden, P. Wouters, H.J. McQueen, E. Aernoudt, L. Delaey, S. Cauwenberg, Mater. Sci. Eng. A 123 (1990) 229-237.

49. C. Badini, F. Marino, E. Verné, Mater. Sci. Eng. A 191 (1995) 185-191.

50. P. Cavaliere, J. Light Metal. 2 (2002) 247-252.

51. N. Jin, H. Zhang, Y. Han, W. Wu, J. Chen, Mater. Charact. 60 (2009) 530-536.

52. I. Charit, R.S. Mishra, J. Mater. Res. 19 (2004) 3329-3342.

53. Y. Huang, J.D. Robson, P.B. Prangnell, Acta Mater. 58 (2010) 1643-1657.

54. D.A. Hughes, Acta Metall. Mater. 41 (1993) 1421-1430.

55. F.J. Humphreys, M. Hatherly. Recrystallization and related annealing phenomenon. $2^{\text {nd }}$ ed. Elsevier; 2004.

56. T.C. Schulthess, P.E.A. Turchia, A. Gonisa, T.-G. Nieh, Acta Mater. 46 (1998) 2215-2221.

57. N.Y. Zolotorevsky, A.N. Solonin, A.Y. Churyumov, V.S. Zolotorevsky, Mater. Sci. Eng. A 502 (2009) 111-117.

58. O. Sivakesavam, I.S. Rao, Y.V.R.K. Prasad, Mater. Sci. Technol. 9 (1993) 805-810.

59. P.J. Apps, J.R. Bowen, P.B. Prangnell, Acta Mater. 51 (2003) 2811-2822.

60. D. Dumont, A. Deschamps, Y. Brechet. Mater. Sci. Eng. A 356 (2003) 326-336.

61. P. Cavaliere, E. Evangelista, Compos. Sci. Technol. 66 (2006) 357-362.

62. I. Sen, R.S. Kottada, U. Ramamurty, Mater. Sci. Eng. A 527 (2010) 6157-6165.

63. H.Z. Li, H.J. Wang, X.P. Liang, Mater. Sci. Eng. A 528 (2011) 1548-1552.

64. E. Hersent, J.H. Driver, D. Piot, Scripta Mater. 62 (2010) 455-457. 


\section{Figure Captions}

Figure 1. Illustration of the flat at a distance of $0.7 \mathrm{R}$ of the torsion sample that was used for microstructural analysis.

Figure 2. Equivalent stress-equivalent strain for the Al 2024 alloy deformed in torsion. The deformation temperatures were in the range $278-467^{\circ} \mathrm{C}$ and the strain rates were (a) $\dot{\varepsilon}=2.1 \mathrm{~s}^{-1}$, (b) $\dot{\varepsilon}=4.5 \mathrm{~s}^{-1}$, (c) $\dot{\varepsilon}=9.6 \mathrm{~s}^{-1}$ and (d) $\dot{\varepsilon}=25.6 \mathrm{~s}^{-1}$.

Figure 3. Plastic strain to failure $\left(\varepsilon_{\mathrm{F}}\right)$ for the $\mathrm{Al} 2024$ alloy plotted as a function of temperature at several strain rates.

Figure 4. Fitting representation of Zener parameter, $\mathrm{Z}=\dot{\varepsilon} \exp (\mathrm{Q} / \mathrm{RT})$, as a function of $\sinh (\alpha \sigma)$ for the Al 2024 alloy. Lines correspond to interval of confidence for fitting and upper and lower limits have probability of $95 \%$.

Figure 5. Two-dimensional map of constant forming efficiency contours corresponding to a projection on the $\dot{\varepsilon}$, T plane.

Figure 6. Two-dimensional representation of the $1^{\text {st }}$ Lyapunov criterion as a function of strain rate and temperature.

Figure 7. Two-dimensional representation of the $2^{\text {nd }}$ Lyapunov criterion as a function of strain rate and temperature.

Figure 8. a) and b) Backscattered electron micrograph and EBSD map, respectively, showing the microstructure of the as-received Al 2024-T351 alloy. c) and d) correspond to EBSD maps of the un-deformed head of the torsioned samples at 467 and $278^{\circ} \mathrm{C}$, respectively.

Figure 9. EBSD maps and corresponding $\{111\}$ pole figures of the Al 2024 alloy torsion tested at $4.5 \mathrm{~s}^{-1}$ and different temperatures: a) $467^{\circ} \mathrm{C}$; b) $408^{\circ} \mathrm{C}$; c) $360^{\circ} \mathrm{C}$ and d) $278^{\circ} \mathrm{C}$; e) main torsion components on the $\{111\}$ pole figure.

Figure 10. Backscattered electron micrographs of the Al 2024 alloy torsion tested at 4.5 $\mathrm{s}^{-1}$ and different temperatures: a) $467^{\circ} \mathrm{C}$; b) $408^{\circ} \mathrm{C}$; c) $360^{\circ} \mathrm{C}$ and d) $278^{\circ} \mathrm{C}$.

Figure 11. Plastic strain to failure $\left(\varepsilon_{\mathrm{F}}\right)$, efficiency and instability parameter according to the $2^{\text {nd }}$ Lyapunov criterion as a function of temperature at two strain rates: a) $4.5 \mathrm{~s}^{-1}$ and b) $25.6 \mathrm{~s}^{-1}$.

Figure 12. EBSD maps and corresponding $\{111\}$ pole figure of the A1 2024 alloy torsion tested at $2.1 \mathrm{~s}^{-1}$ and $408^{\circ} \mathrm{C}$. a) Inverse pole figure (IPF) map which has been colour coded according to the IPF shown in the inset of the Fig. 8b; b) Kikuchi band contrast (BC) map with high-angle boundaries $\left(>15^{\circ}\right)$ in black and low-angle boundaries $\left(2^{\circ}-15^{\circ}\right)$ in green. 


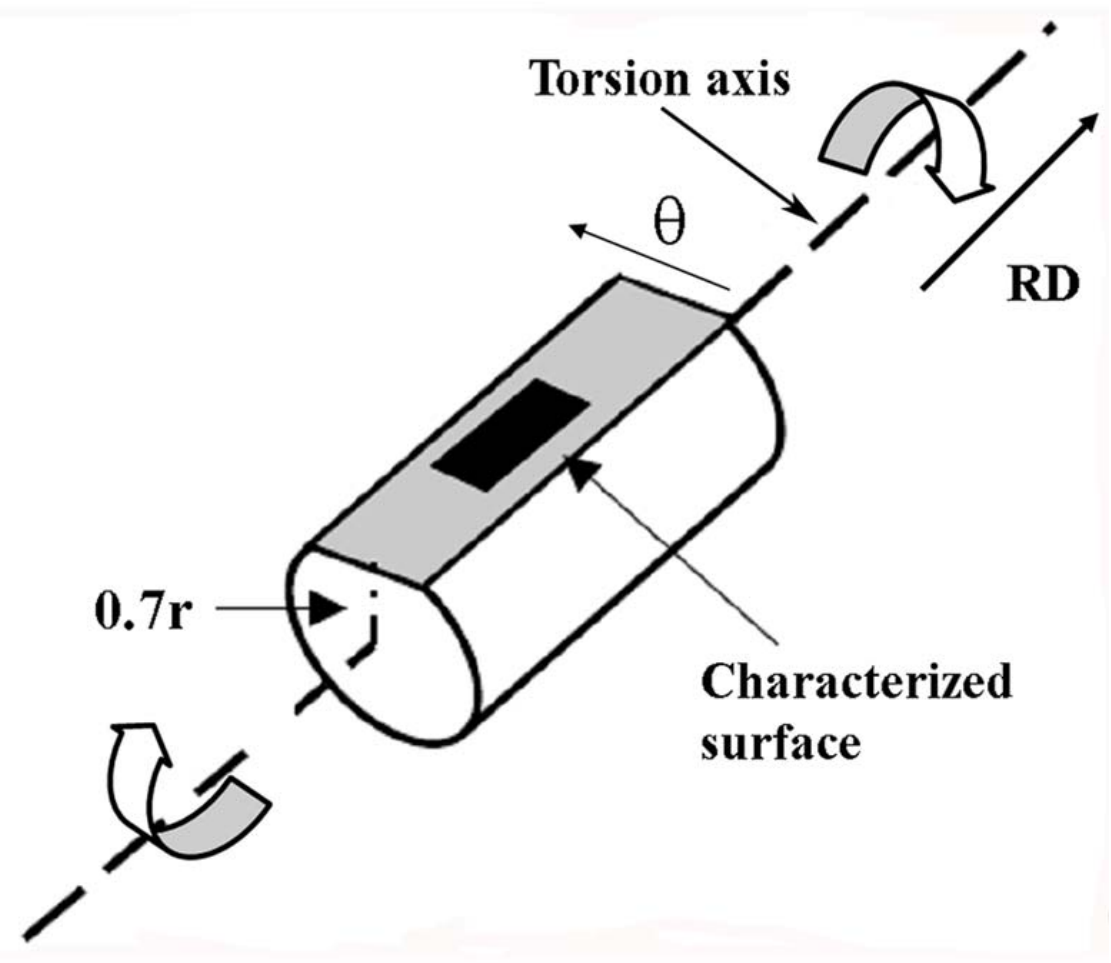

Figure 1. Illustration of the flat at a distance of $0.7 \mathrm{R}$ of the torsion sample that was used for microstructural analysis. 

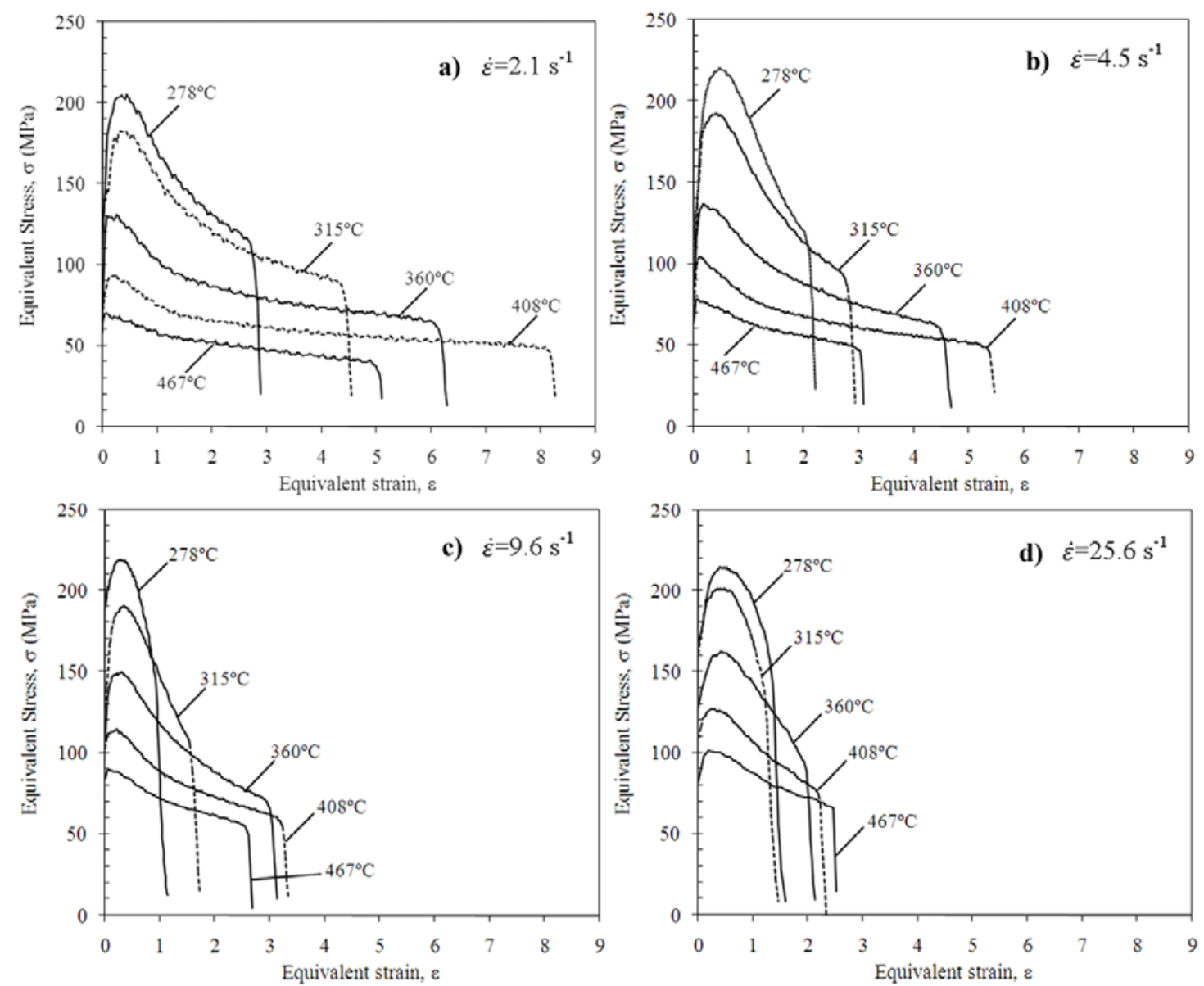

Figure 2. Equivalent stress-equivalent strain for the Al 2024 alloy deformed in torsion. The deformation temperatures were in the range $278-467^{\circ} \mathrm{C}$ and the strain rates were (a) $\dot{\varepsilon}=2.1 \mathrm{~s}^{-1}$, (b) $\dot{\varepsilon}=4.5 \mathrm{~s}^{-1}$, (c) $\dot{\varepsilon}=9.6 \mathrm{~s}^{-1}$ and (d) $\dot{\varepsilon}=25.6 \mathrm{~s}^{-1}$. 


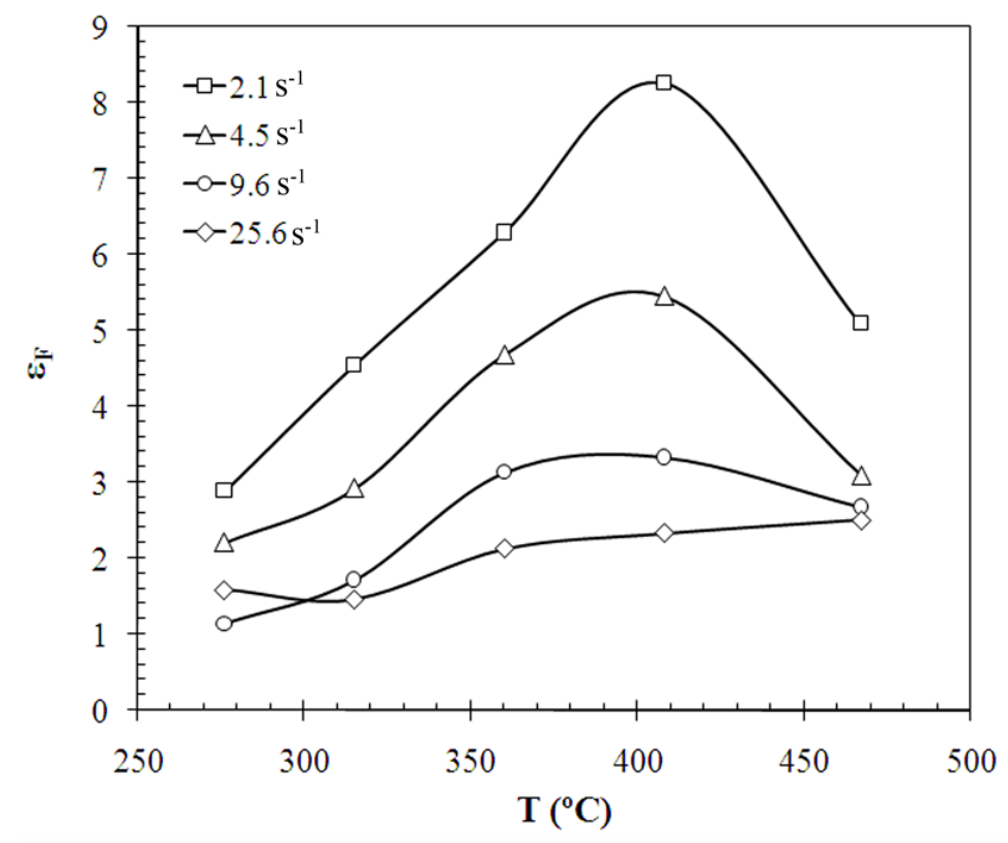

Figure 3. Plastic strain to failure $\left(\varepsilon_{\mathrm{F}}\right)$ for the $\mathrm{Al} 2024$ alloy plotted as a function of temperature at several strain rates.

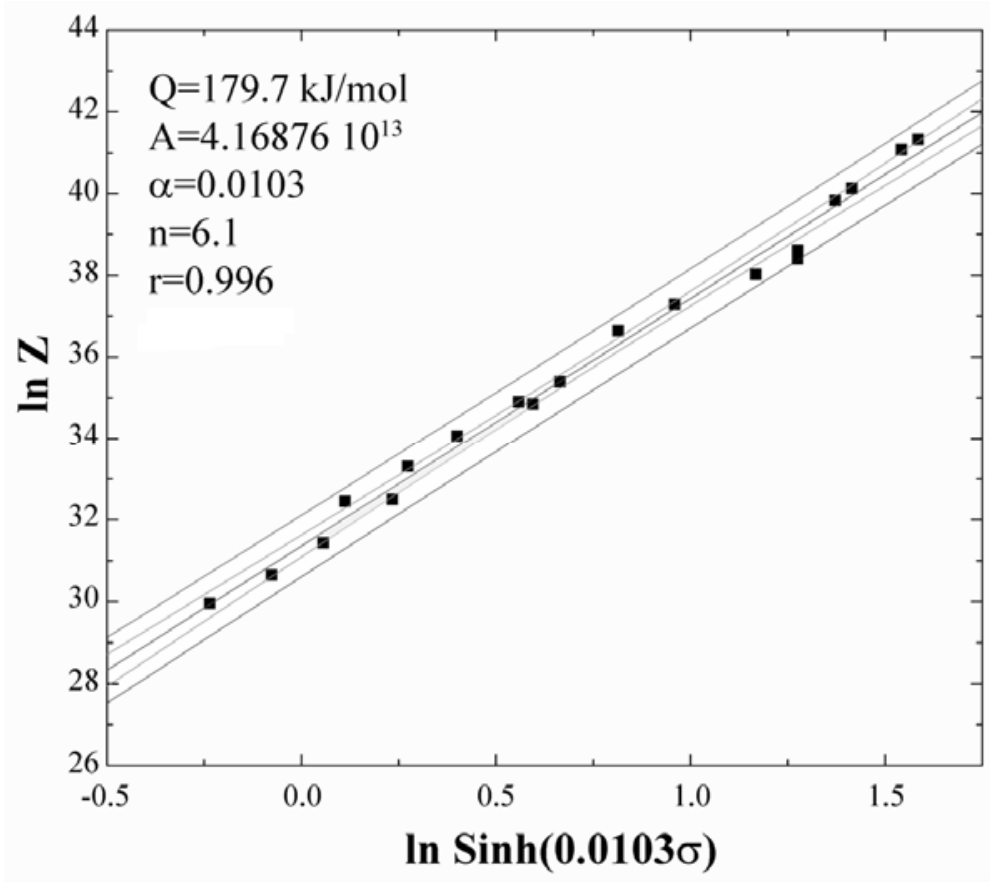

Figure 4. Fitting representation of Zener parameter, $Z=\dot{\varepsilon} \exp (\mathrm{Q} / \mathrm{RT})$, as a function of $\sinh (\alpha \sigma)$ for the A1 2024 alloy. Lines correspond to interval of confidence for fitting and upper and lower limits have probability of $95 \%$. 


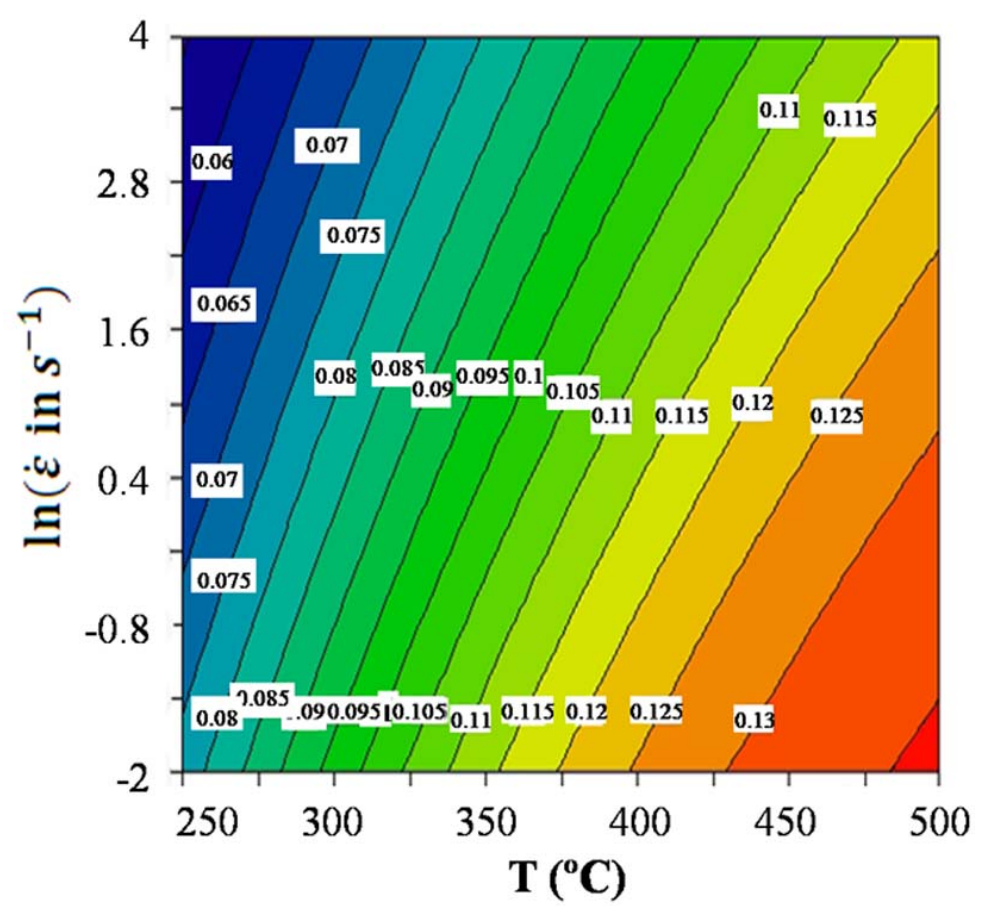

Figure 5. Two-dimensional map of constant forming efficiency contours corresponding to a projection on the $\dot{\varepsilon}$, T plane.

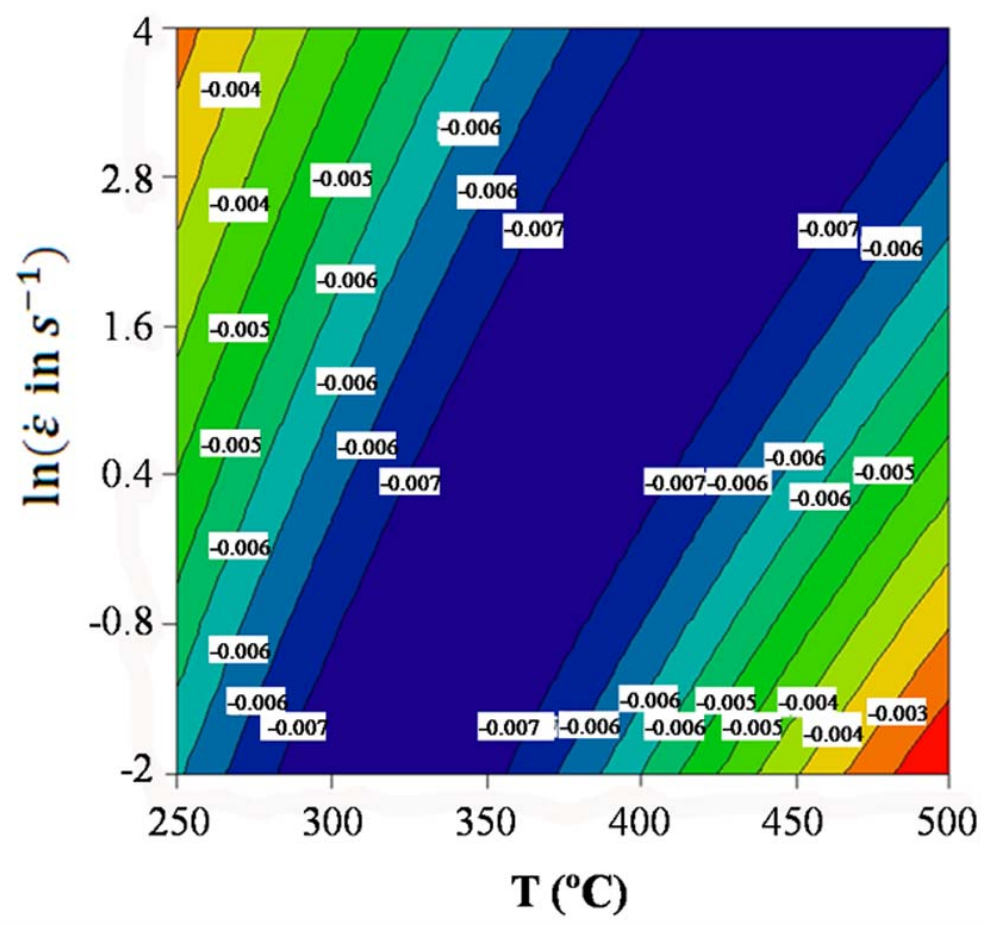

Figure 6. Two-dimensional representation of the $1^{\text {st }}$ Lyapunov criterion as a function of strain rate and temperature. 


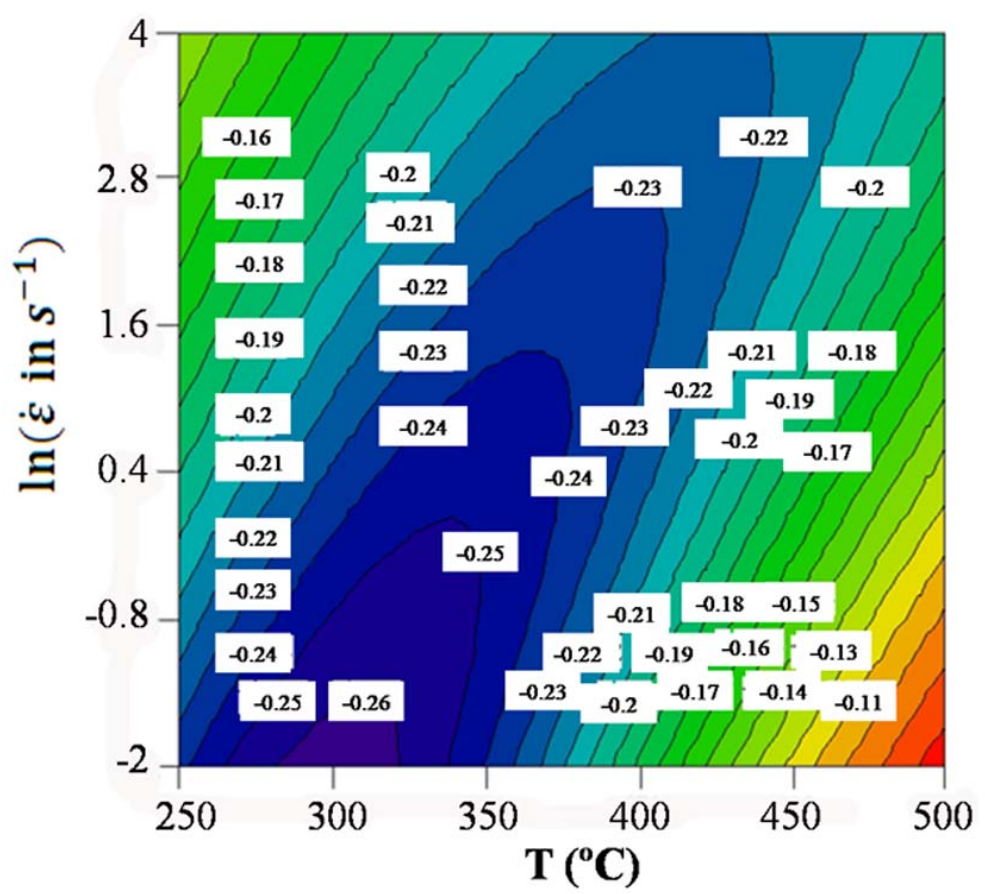

Figure 7. Two-dimensional representation of the $2^{\text {nd }}$ Lyapunov criterion as a function of strain rate and temperature.

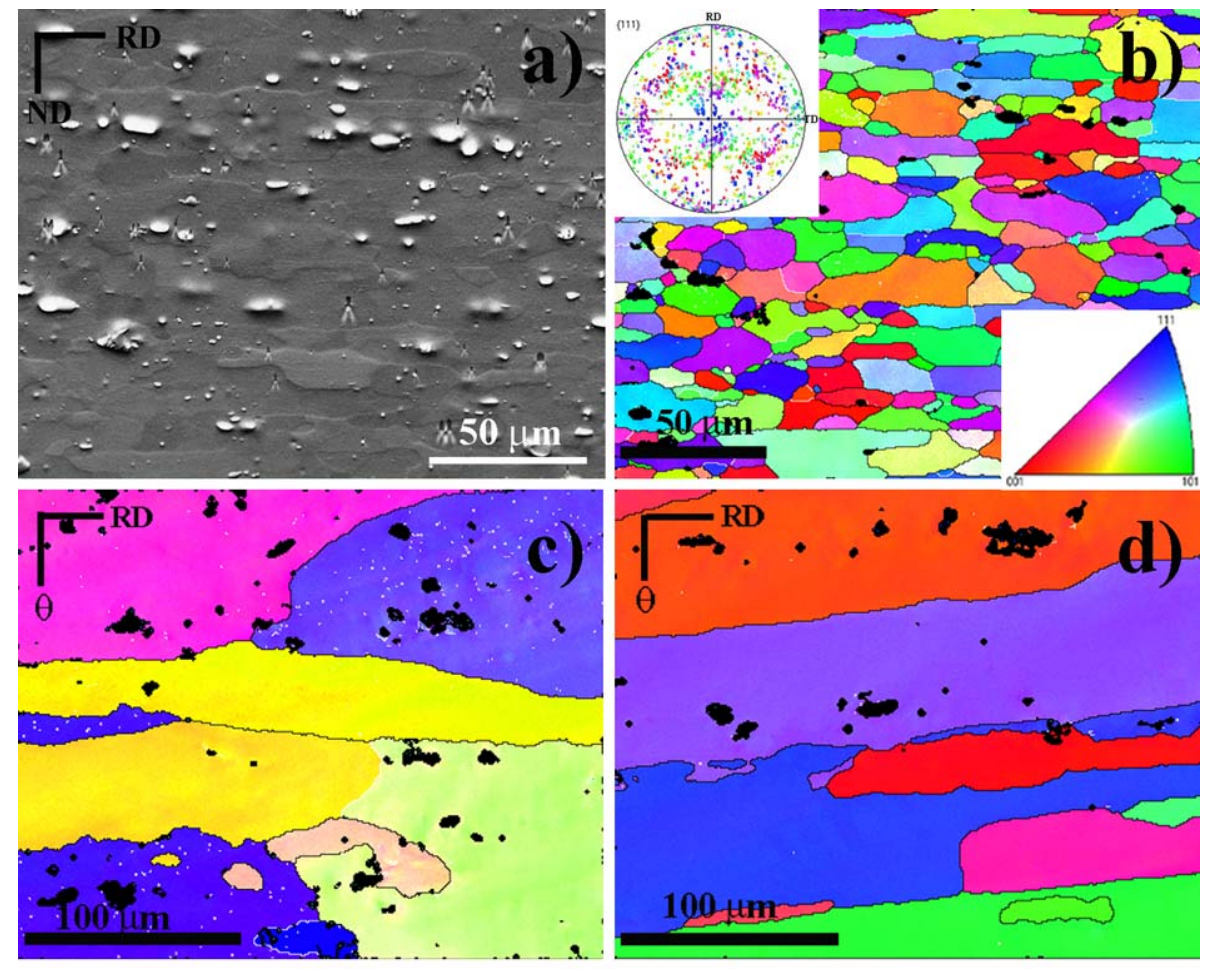

Figure 8. a) and b) Backscattered electron micrograph and EBSD map, respectively, showing the microstructure of the as-received Al 2024-T351 alloy. c) and d) correspond to EBSD maps of the un-deformed head of the torsioned samples at 467 and $278^{\circ} \mathrm{C}$, respectively. 


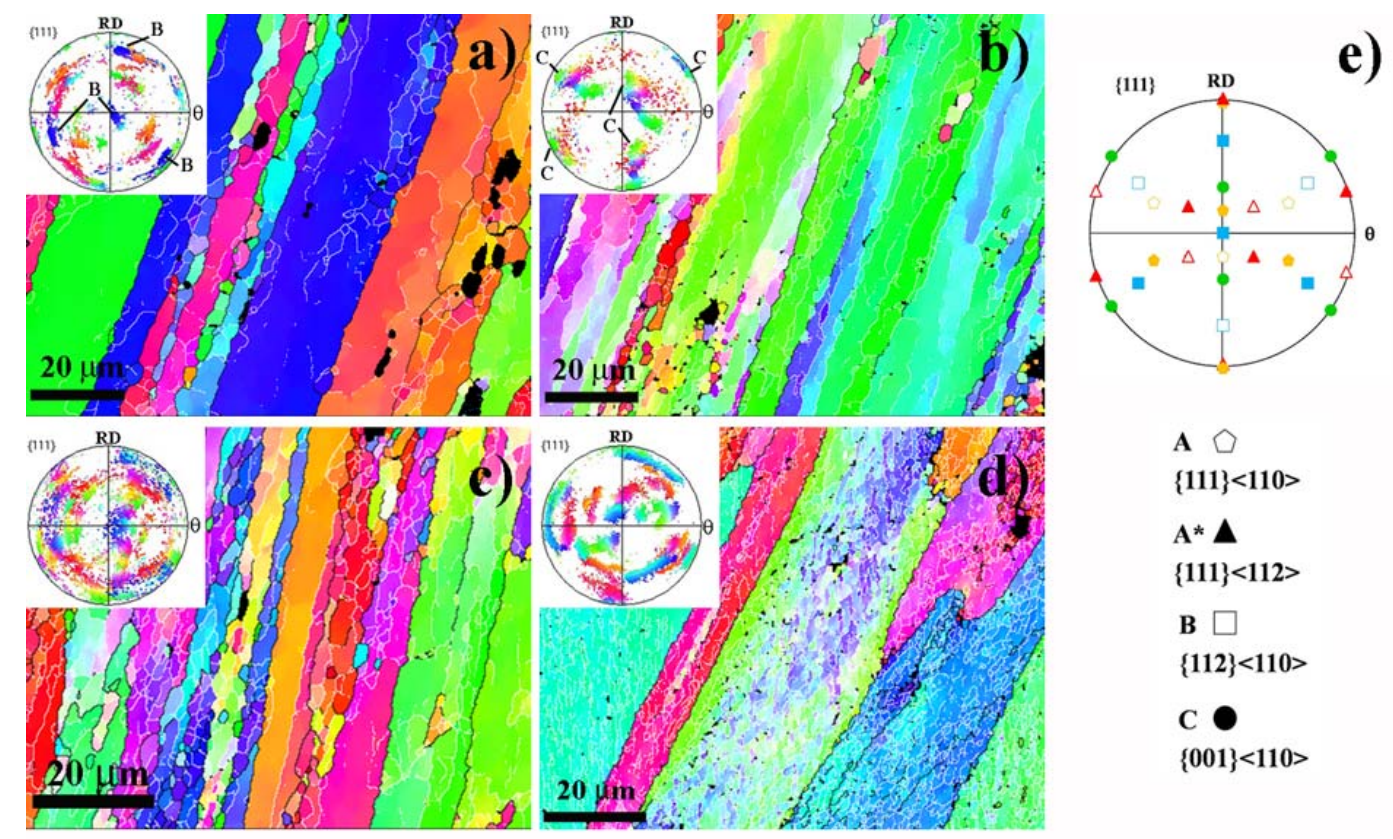

Figure 9. EBSD maps and corresponding $\{111\}$ pole figures of the Al 2024 alloy torsion tested at $4.5 \mathrm{~s}^{-1}$ and different temperatures: a) $467^{\circ} \mathrm{C}$; b) $408^{\circ} \mathrm{C}$; c) $360^{\circ} \mathrm{C}$ and d) $278^{\circ} \mathrm{C}$; e) main torsion components on the $\{111\}$ pole figure.

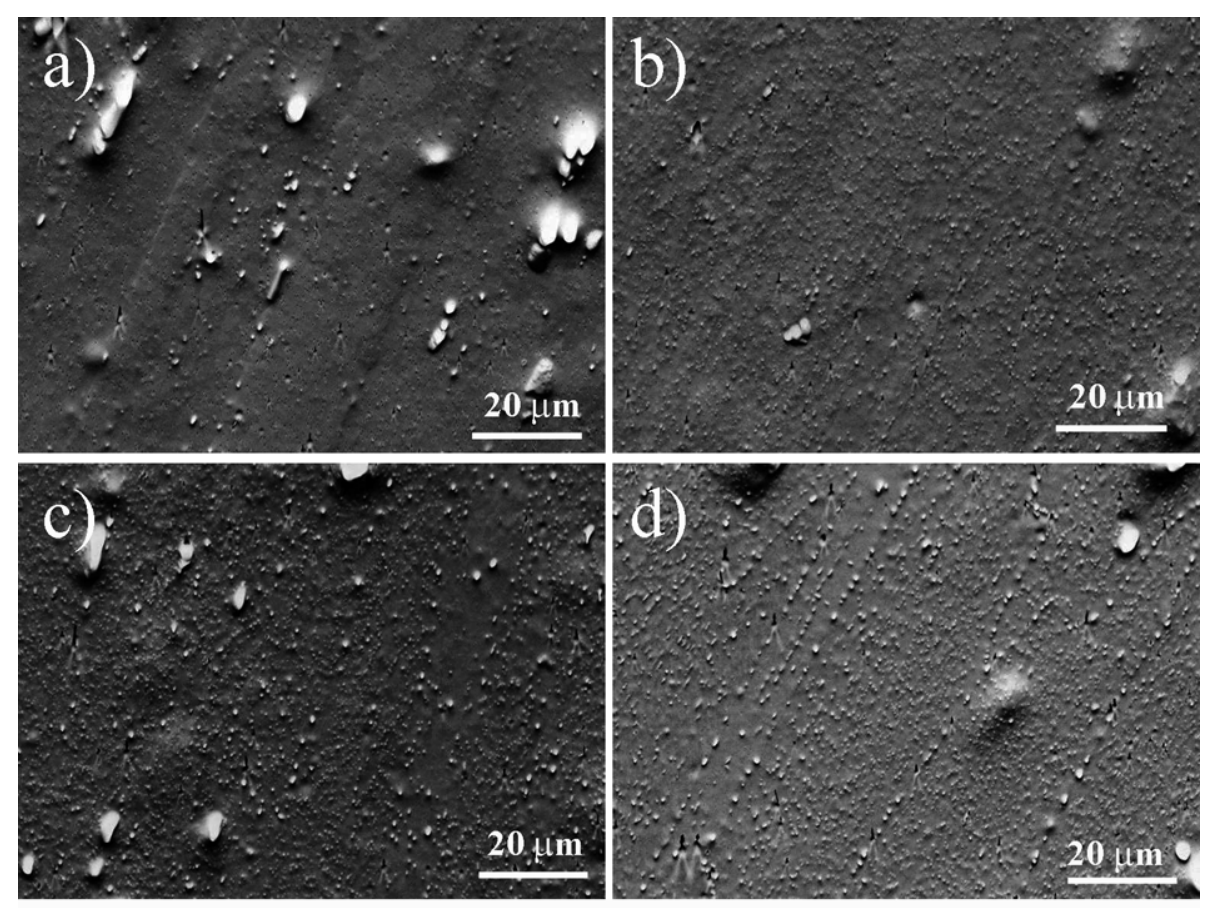

Figure 10. Backscattered electron micrographs of the Al 2024 alloy torsion tested at 4.5 $\mathrm{s}^{-1}$ and different temperatures: a) $467^{\circ} \mathrm{C}$; b) $408^{\circ} \mathrm{C}$; c) $360^{\circ} \mathrm{C}$ and d) $278^{\circ} \mathrm{C}$. 


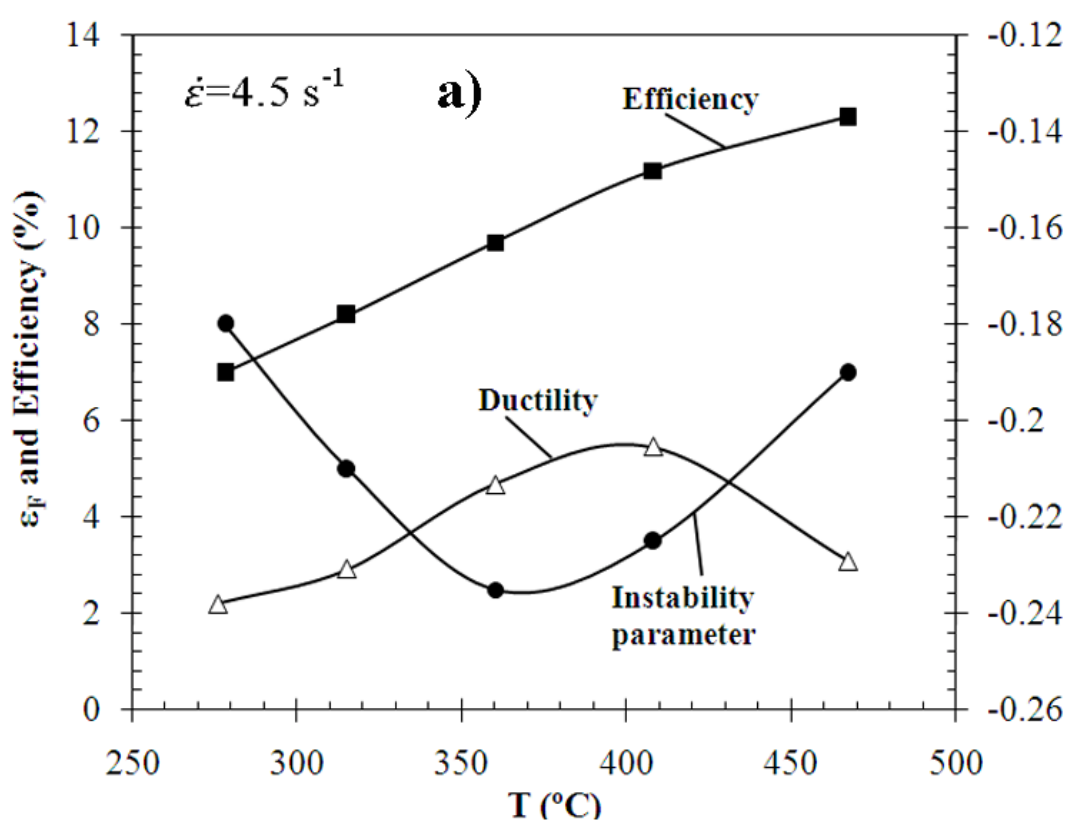



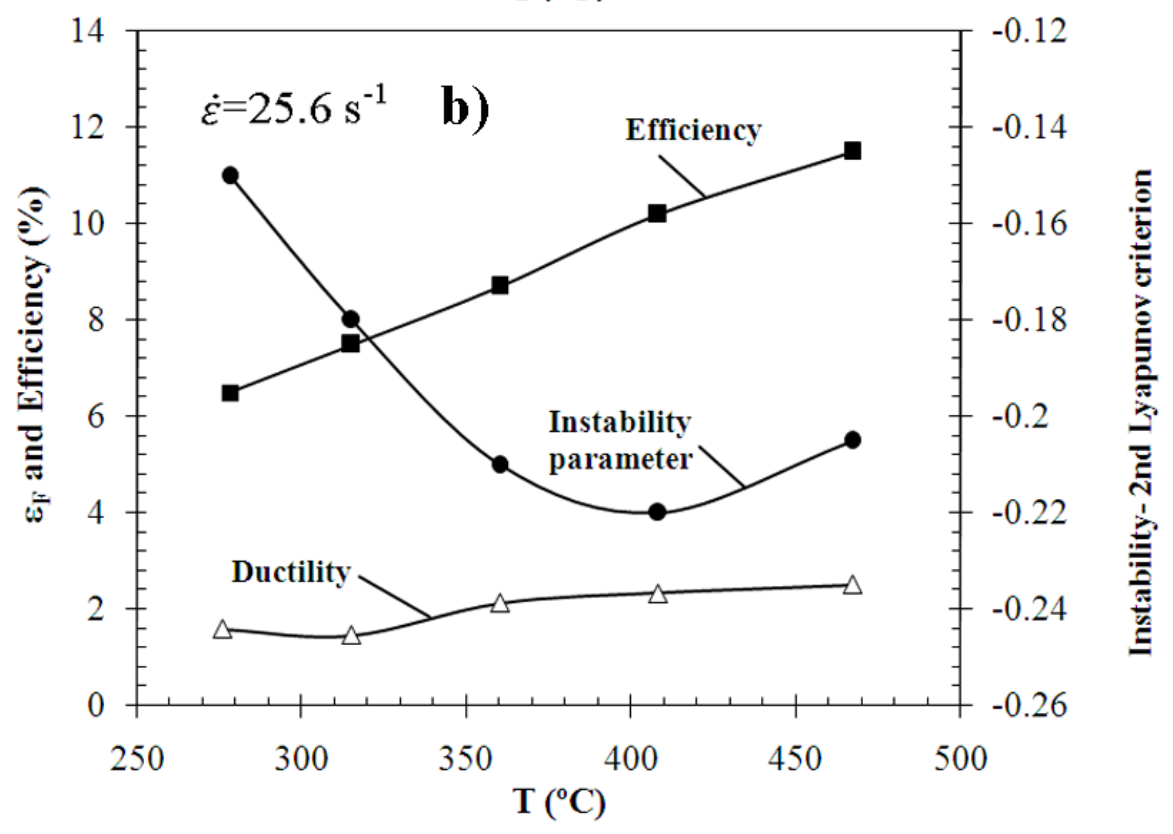

Figure 11. Plastic strain to failure $\left(\varepsilon_{\mathrm{F}}\right)$, efficiency and instability parameter according to the $2^{\text {nd }}$ Lyapunov criterion as a function of temperature at two strain rates: a) $4.5 \mathrm{~s}^{-1}$ and b) $25.6 \mathrm{~s}^{-1}$. 

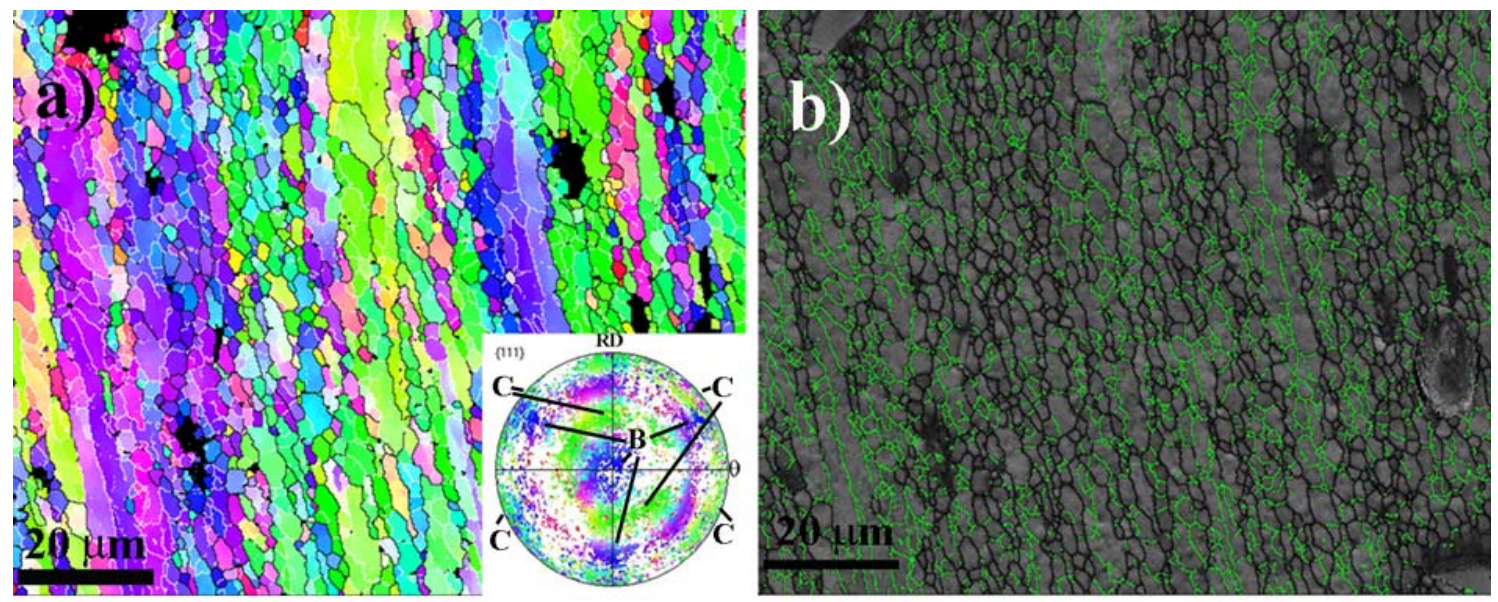

Figure 12. EBSD maps and corresponding $\{111\}$ pole figure of the Al 2024 alloy torsion tested at $2.1 \mathrm{~s}^{-1}$ and $408^{\circ} \mathrm{C}$. a) Inverse pole figure (IPF) map which has been colour coded according to the IPF shown in the inset of the Fig. 8b; b) Kikuchi band contrast (BC) map with high-angle boundaries $\left(>15^{\circ}\right)$ in black and low-angle boundaries $\left(2^{\circ}-15^{\circ}\right)$ in green. 